\title{
Soil Salinity Mapping by Multiscale Remote Sensing in Mesopotamia, Iraq
}

\author{
Weicheng Wu, Waleed M. Al-Shafie, Ahmad S. Mhaimeed, Feras Ziadat, Vinay Nangia, and William Bill Payne
}

Abstract-Soil salinity has become one of the major problems affecting crop production and food security in Mesopotamia, Iraq. There is a pressing need to quantify and map the spatial extent and distribution of salinity in the country in order to provide relevant references for the central and local governments to plan sustainable land use and agricultural development. The aim of this study was to conduct such quantification and mapping in Mesopotamia using an integrated, multiscale modeling approach that relies on remote sensing. A multiyear, multiresolution, and multisensor dataset composed of mainly Landsat ETM+ and MODIS data of the period 2009-2012 was used. Results show that the localscale salinity models developed from pilot sites with vegetated and nonvegetated areas can reliably predict salinity. Salinity maps produced by these models have a high accuracy of about $82.5-83.3 \%$ against the ground measurements. Regional salinity models developed using integrated samples from all pilot sites could predict soil salinity with an accuracy of $80 \%$ based on comparison to regional measurements along two transects. It is hence concluded that the multiscale models are reasonably reliable for assessment of soil salinity at local and regional scales. The methodology proposed in this paper can minimize problems induced by crop rotation, fallowing, and soil moisture content, and has clear advantages over other mapping approaches. Further testing is needed while extending the mapping approaches and models to other salinity-affected environments.

Index Terms-Multiscale remote sensing, multiyear maxima, new processing algorithm, salinity models, soil salinity. PPROXIMATELY, $60 \%$ of the cultivated land in the Mesopotamian plain in Iraq is seriously affected by salinity [1]; 20-30\% has been abandoned in the past 4000 years [1], [2]. Because of soil salinity, yield of crops, especially, wheat of nonabandoned has declined by $20-50 \%$ by 1950 s [2]. But

Manuscript received November 14, 2013; revised July 09, 2014; accepted September 18, 2014. This work was supported in part by the Australian Center for International Agricultural Research (ACIAR) and in part by the Italian Government. (Corresponding author: Weicheng Wu.)

W. Wu was with the International Center for Agricultural Research in the Dry Areas (ICARDA), 11195 Amman, Jordan. He is now an independent scientist in Choisy-Le-Roi 94600, France (e-mail: wuwc123@gmail.com).

W. M. Al-Shafie is with the GIS Division, Ministry of Agriculture (MoA), 10001 Baghdad, Iraq.

A. S. Mhaimeed is with the College of Agriculture, Baghdad University, 00964 Baghdad, Iraq.

F. Ziadat and V. Nangia are with the Integrated Water and Land Management Program (IWLM), ICARDA, 11195 Amman, Jordan.

W. B. Payne was with ICARDA, 11195 Amman, Jordan. He is now with the College of Agriculture, Biotechnology and Natural Resources (CABNR), University of Nevada, Reno, NV 89557-0221, USA

Color versions of one or more of the figures in this paper are available online at http://ieeexplore.ieee.org.

Digital Object Identifier 10.1109/JSTARS.2014.2360411 the severity and distribution of soil salinity varies with space and time [2]-[4]. In order to prioritize any remediation effort and better plan for agricultural improvements and food security, it is of prime importance for Iraqi central and local governments to understand the distribution and severity of salinity in Mesopotamia.

Soil salinity is a common form of land degradation in irrigated areas located in dryland environments [5]-[8]. The physical appearance of salinity is strongly influenced by soil properties (e.g., moisture, texture, mineral composition, and surface roughness) as well as type of vegetation cover (e.g., halophyte and nonhalophyte, salt-tolerant and nonsalt-tolerant) [5]-[8]. Remote sensing has been widely applied for mapping and assessment of soil salinity in recent decades using vegetation indices (VIs) and combined spectral response index (COSRI) [9]-[16], best band combination [17], [18], maximum likelihood and fuzzy logic-based classifications [19]-[23], principal component analysis (PCA), surface feature unmixing, and data fusion [6], [7], [24]. Predictive models have been developed for soil salinity using different regression analysis, artificial neural network (ANN), and Kriging/CoKriging techniques [9]-[16], [18], [24]-[26]. Very recently, along with vegetation indices and reflectance of certain spectral bands, evapotranspiration (ET) and land surface temperature (LST) have been used to predict salinity in salt-affected areas [16], [27]-[29].

While these and other studies demonstrate the feasibility, advantages, and potential of remote sensing to assess soil salinity, there remain certain challenges. First, although in strongly salinized areas, salt tends to concentrate on terrain surfaces and can be easily detected by conventional remote sensing tools; however, for low-to-moderate salinity (salt $<10-15 \%$ ), spectral confusions with other different surface features may arise leading to identification failure (either overestimation or underestimation) [6], [7]; especially, when salt concentrates in subsoil, optical remote sensing is restricted [8]. Second, soil moisture, halophyte vegetation, and salt-tolerant crops such as barley, cotton, and alfalfa can modify the overall spectral response pattern of salt-affected soils, especially in the green and red bands [6], [7], [30]. Third, lands in the states of fallow, noncrop interval in-between rotations, and crop rotations tend to be interpreted as salinized areas if only soil bareness or vegetation greenness of a single image is investigated. To avoid these problems, some authors have suggested: 1) to use images acquired at the end of dry or hot season or of multiple cropping periods [7], [8], 2) to conduct regression analysis against VIs [9]-[16] and geophysical measurement [8] in combination with 
soil sampling and analysis. These are, no doubt, useful suggestions to minimize the mentioned problems and accomplish a better mapping work. However, most of the available studies have employed single or multidate single images to assess salinity at local scale, and their approaches are not fully repeatable or extendable for regional-scale assessment due to spatial variability and diversity in climate conditions, soil properties, and land use/management. It is, therefore, essential to develop new processing methods and approaches technically operational for regional-scale salinity mapping.

The main objectives of this study are, hence, to develop an integrated methodology operational for regional salinity quantification and assessment based on the available approaches considering the above-mentioned problematic issues, to provide relevant multiscale salinity maps for Iraqi governments, and finally, to lay a foundation for the successive regional-scale tracking of salinity change trends in space and time that may provide spatial reference for the governments to understand the impacts of land management on salinization processes in Mesopotamia.

As well as for salinity assessment, remote sensing technology has also been widely applied in other dryland research. Some scientists have utilized annual maximum (peak) VIs such as Normalized Difference Vegetation Index (NDVI) [31] to compose cloud-free NDVI [32]-[35] for assessing dryland biomass [33]-[35] and land degradation [35]-[37] in the past decades. Others have used multiyear maximum (peak) and minimum (trough) NDVI and LST to derive vegetation condition index (VCI) and temperature condition index (TCI) for monitoring droughts [38]-[40]. Clearly, annual maximum VI, if applied to salinity assessment, can resolve the problems related to cloud-cover and crop rotation (crops cultivated either in spring or summer) but cannot remove that resulted from fallow state which may last a couple of years. However, multiyear maximum, if the observation period spans 3-4 years, can minimize (if cannot completely resolve) these problems. LST is associated with soil moisture and water content [41]-[44], and high LST is related to low moisture [44]. Thus, multiyear maximal LST is a promising indicator to minimize the problem related to soil moisture.

Additionally, remote sensing-based multiscale modeling has gained a momentum in regional, continental or even global scale application [34], [45], [46] to extend plot measurements to local-scale (e.g., pilot site or watershed), and then to regionalor continental-scale [34], [46]. As Farifteh et al. [8] and $\mathrm{Wu}$ et al. [34] explained, such multiscale modeling is in fact an upscaling procedure to extend models developed from local studies to regional-scale assessment considering the spatial variability.

From the above brief review, we reached an understanding that regional salinity mapping and assessment require integrated approaches which consider multidimensional (or multiaspect) observation and analysis from surface (e.g., vegetated and nonvegetated areas) to subsoil (within a limited depth of, e.g., $<150 \mathrm{~cm}$ ), and from multiple biophysical characterization to traditional soil sampling. We propose, hence, in this paper a "multiyear maxima and multiscale modeling" methodology for salinity quantification in Mesopotamia, Iraq.

\section{Materials And Methods}

\section{A. Study Area}

Mesopotamia, "the land between rivers" in ancient Greek and 144 encompassing a surface area of about $135000 \mathrm{~km}^{2}$, is a typ- 145 ical alluvial plain between the two famous rivers, Euphrates 146 and Tigris (Fig. 1) and the home of multiple ancient civiliza- 147 tions namley Sumerian, Akkadian, Babylonian, and Assyrian 148 [4]. As an arid subtropical region, the climate is characterized 149 by dry hot summers and cooler winters [2], [3], [29], where 150 annual rainfall is mostly below $200 \mathrm{~mm}$, of which the average 151 is $110 \mathrm{~mm}$ in Baghdad and $149 \mathrm{~mm}$ in Basrah in the past three 152 decades. The mean maximum and minimum temperatures are 153 $44^{\circ} \mathrm{C}$ and $25.6^{\circ} \mathrm{C}$, respectively, in Baghdad, $46^{\circ} \mathrm{C}$ and $29.15^{\circ} \mathrm{C} 154$ in Basrah in July-August, whereas they are $16.5^{\circ} \mathrm{C}$ and $4.8^{\circ} \mathrm{C} 155$ in Baghdad, $19^{\circ} \mathrm{C}$ and $8.4^{\circ} \mathrm{C}$ in Basrah in December-January. 156

As a fluviatile plain, soils are extremely calcareous (20-30\% 157 lime) alluvial silty loam or loamy silts [2], [3], typical 158 Fluvisols in terms of WRB (the World Reference Base for 159 Soil Resources), and mostly saline as a result of cumula- 160 tive salinization in the past 6000 years [2]-[4]. Archeological 161 evidence revealed that crop cultivation (e.g., wheat and bar- 162 ley) was started as early as $4000 \mathrm{BC}$ in Mesopotamia [2], 163 [4]. Due to aridity, farming is impossible if not irrigated. 164 Irrigation increases soil moisture and crop production, nonethe- 165 less, leads to elevation of water-table or water-logging in the 166 area where there is no drainage or draining is slow [2]-[4]. 167 Consequently, salts accumulate in soils after evaporation and 168 transpiration year by year. According to Jacobsen and Adams 169 [4], salinity had already become a serious hazard in south- 170 ern Mesopotamia in the late Sumerian or early Akkadian 171 periods, e.g., around 2400-2300 BC, and led to a decline 172 in wheat production. The proportions of wheat and barley 173 were nearly equal in about $3500 \mathrm{BC}$ but became 1 to 6174 in $2400 \mathrm{BC}$ in Girsu (nowadays Thi-Qar); wheat cultivation 175 was completely abandoned after $1700 \mathrm{BC}$ and land produc- 176 tivity declined from $2537 \mathrm{l} / \mathrm{ha}$ before $2400 \mathrm{BC}$ to $897 \mathrm{l} / \mathrm{ha}$ in 177 $1700 \mathrm{BC}$ in Larsa (also in Thi-Qar) as a consequence of salin- 178 ization. Salinity is hence an old problem that contributed to 179 the breakup of ancient civilization [4]. Unfortunately, saliniza- 180 tion has never stopped but progressively extended to the whole 181 Mesopotamian plain to the state as described in the beginning 182 of the paper.

As Buringh investigated [2], the most common salt in 184 saline soils is sodium chloride $(\mathrm{NaCl})$ followed by other 185 chlorides (e.g., $\mathrm{CaCl}_{2}, \mathrm{MgCl}_{2}$, and $\mathrm{KCl}$ ), and sulfates (e.g., 186 $\mathrm{CaSO}_{4} \cdot 2 \mathrm{H}_{2} \mathrm{O}, \mathrm{Na}_{2} \mathrm{SO}_{4} \cdot 10 \mathrm{H}_{2} \mathrm{O}$, and $\mathrm{MgSO}_{4}$ ). Saline-alkaline 187 soils may exist locally but real alkali soils (in black) are very 188 scarce in Mesopotamia.

\section{B. Field Sampling Design and Data}

To achieve our objectives, comprehensive observations and 191 measurements at different scales are required. The experi- 192 ment was hence designed to be conducted at three levels, i.e., 193 plot, local (pilot site), and regional scales, corresponding to 194 the proposed multiscale approach. Both local (pilot site)- and 195 


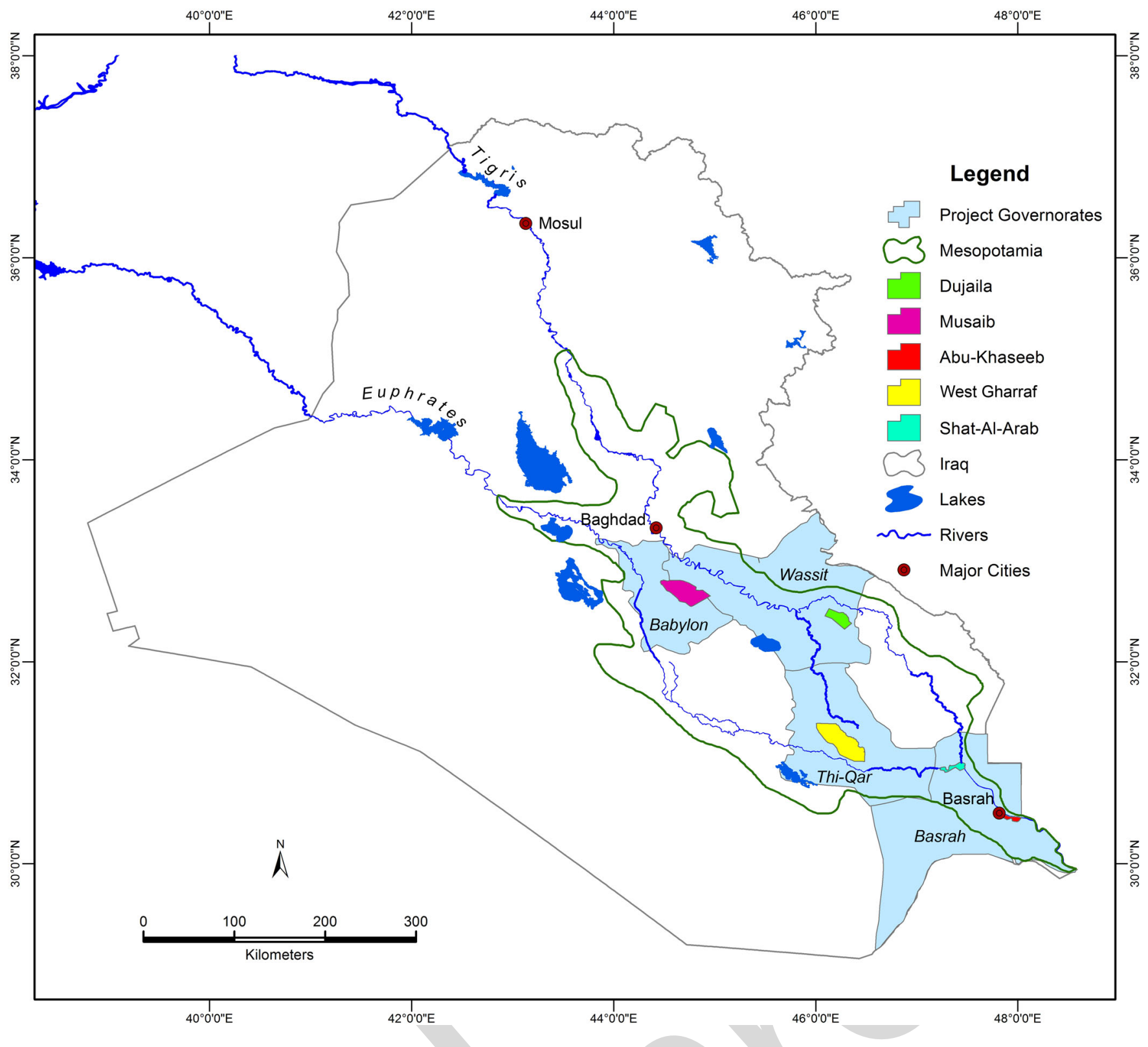

F1:1 Fig. 1. Location of the five pilot sites and the whole study area, Mesopotamia, in Iraq.

regional-scale surveys were composed of plot level investigation and measurements.

Plot level survey included land use/cover investigation, crop types and performance observation (if possible), soil sampling, and apparent salinity measurement using a ground conductivity meter, EM38-MK2 (Geonics Ltd.), in an area of $1 \mathrm{~m} \times 1 \mathrm{~m}$. EM38 meter is capable to measure the apparent soil salinity in both horizontal (with a measurement depth up to $50 \mathrm{~cm}$ ) and vertical (up to $150 \mathrm{~cm}$ ) directions, of which the readings can be respectively denoted as $\mathrm{EM}_{\mathrm{H}}$ (horizontal) and $\mathrm{EM}_{\mathrm{V}}$ (vertical) in millisiemens per meter $(\mathrm{mS} / \mathrm{m})$. Hence, EM38 meter can reveal salinity of both surface and subsoil. However, the apparent salinity has to be calibrated by laboratory measured soil salinity. The false salinity caused by metal and/or soil moisture should be avoided while measurement is conducted.
In order to be comparable with the pixels of high-resolution 212 satellite images such as Landsat and SPOT (e.g., 10-30 m), the 213 survey was planned to be conducted in three plots distributed 214 at three corners of a triangle, respectively, with a distance of 215 about $15-20 \mathrm{~m}$ from each other in the same patch of land. The 216 averaged values of the EM38 readings including both $\mathrm{EM}_{\mathrm{V}}$ and 217 $\mathrm{EM}_{\mathrm{H}}$ of the three corner plots would be taken to represent the 218 salinity of the center of the observed triangle. Soil samples for 219 laboratory chemical analysis were to be taken from soil profiles 220 at the depth of 0-30, 50-70, 90-110 and 120-150 cm, and from 221 surface $(0-30 \mathrm{~cm}$ in depth) using auger tools in the plots where 222 EM38 was also measured.

Pilot site level survey was to serve for integrated pilot 224 study, e.g., salinity model development and mapping at local 225 scale. As recommended by the Iraqi government, five sites 226 namely Musaib, Dujaila, West Gharraf, Shat-Al-Arab, and Abu 227 


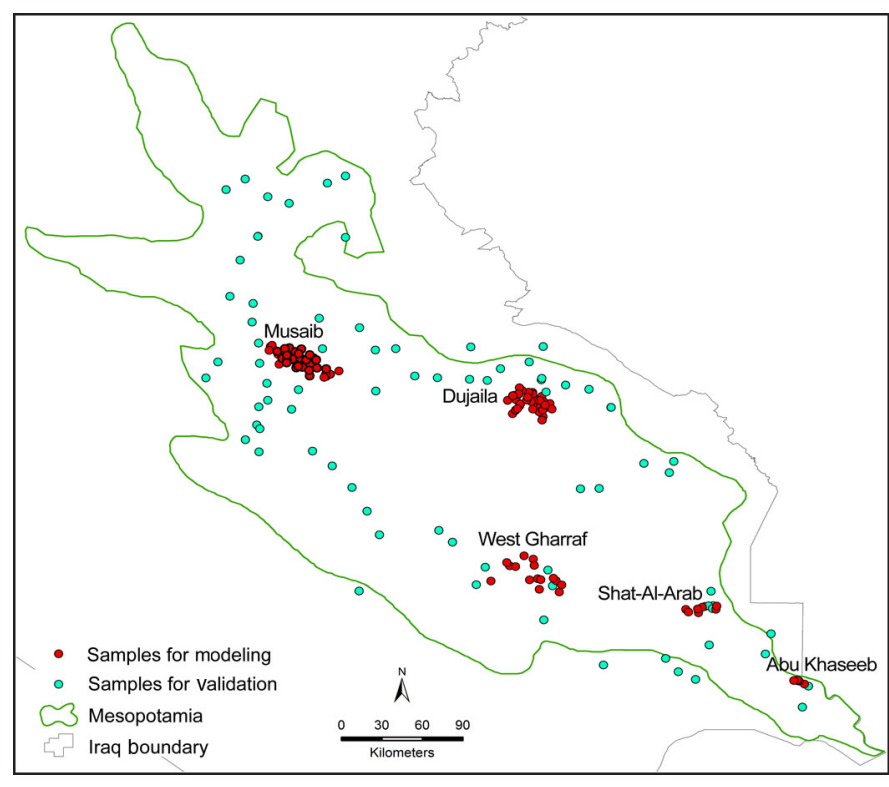

F2:1 Fig. 2. Distribution of the sampling points for modeling and validation.

Khaseeb in the Mesopotamian plain (see Figs. 1 and 2 for location) were selected for pilot studies. It was planned that each pilot site should contain $>5$ soil profiles and $>20$ triangles of plots for surface survey if accessibility allowed.

Regional survey, which was aimed at salinity model development and validation at regional-scale, was to be conducted along two transects in the whole Mesopotamian Plain.

Based on the above design, field survey and sampling campaigns were conducted in the five pilot sites in the period September 2011-July 2012 and along two regional transects in Mesopotamia in April 2012 and June 2013. The sampling locations for plot level survey both in pilot sites and along the regional transects were randomly selected in the field in terms of accessibility. Due to limited budget, surface soil samples were not taken in each plot but at least in one of the three corners. Soil salinity, expressed as electrical conductivity (EC) in decisiemens per meter $(\mathrm{dS} / \mathrm{m})$, was measured in laboratory using 1:1 dilution method. In total, 187 surface soil samples $(0-30 \mathrm{~cm})$ with laboratory analysis and 485 pairs of EM38 measurements were obtained for this study. Sites, depths, and numbers of sampling are described in Table I.

In order to extend plot level measurements to pilot site, and then to regional-scale salinity mapping, a multiyear dataset consisting of multiresolution and multisensor satellite imagery was prepared based on the availability of images. This dataset includes 33 spring (February-April) and summer (August) Landsat ETM+ images of the period 2009-2012, four SPOT 4 images acquired in March 2010, and three RapidEye images dated April 2012, time-series of MODIS vegetation indices data (MOD13Q1), and LST (MOD11A1 and A2) from 2009 to 2012 .

\section{Local-Scale Modeling and Mapping}

As indicated in Section I, apart from the geophysical survey by EM38 meter to understand salinity in surface and subsoil, different remote sensing indicators that can characterize the 262 multiaspect surface biophysical features, e.g., VIs, LST, soil 263 brightness (albedo), and principal components (PCs), need to 264 be derived.

Instead of using one single image, a 4-year imagery dataset 266 registered both spring and summer acquisitions, which was 267 used to derive the multiyear maximal values of a set of VIs and 268 nonvegetation indices (NonVIs) for each pixel. This would help 269 avoiding some false alarm of salinity arising from fallowing, 270 crop rotation, and variation in soil moisture. This processing 271 can also largely remove the problem caused by the image gaps 272 left by the Scan-Line Corrector failure (SLC-Off) in the Landsat 273 ETM+ imagery since 2003. We assumed that it is always possi- 274 ble for a given piece of cropland to be cultivated in either spring 275 or summer with normal performance in the observed period 276 because fallow state lasts, in general, 2-3 years in Central and 277 Southern Iraq.

Image processing in combination with field survey would 279 allow the identification of the salt-tolerant areas, and the con- 280 centration of salt in subsoil, for example, areas with high 281 vegetation greenness but moderate salinity as revealed by the 282 readings of EM 38 or as measured by soil laboratory analy- 283 sis. Such areas have to be defined for a specific analysis since 284 salinity cannot be reflected by vegetation indices.

Furthermore, it is essential to separate vegetated and non- 286 vegetated areas, as the expression of salinity in remote sensing 287 images is different in these two types of areas. For exam- 288 ple, the low values of VIs in nonvegetated areas (e.g., bare 289 soil and desert) do not mean that they are all strongly salin- 290 ized (high salinity). As a matter of fact, salinity is negatively 291 correlated with VIs such as NDVI [11], [13], [28], [29], and 292 it tends to be overestimated in the nonvegetated areas just 293 based on VI-related models. We have to consider the inte- 294 grated information from multiple spectral and thermal bands, 295 e.g., spectral reflectance, LST, PCs, and the brightness of 296 the Tasseled Cap transformation (TCB) [47]-[49], for salin- 297 ity assessment in these areas. The rationale behind is that 298 the spectral reflectance and its multiband linear combination 299 (e.g., TCB and PCs) together with LST might be able to 300 highlight the subtle difference in soil brightness (or albedo) 301 corresponding to the difference in salinity in the nonvegetated 302 areas.

The procedure for local-scale study in the pilot sites is 304 presented as follows.

1) Atmospheric correction using FLAASH model [50] for all 306 Landsat ETM+, SPOT, and RapidEye images.

2) Multispectral transformation: A set of most frequently 308 applied VIs such as NDVI [31], SAVI (soil-adjusted 309 vegetation index) [51], SARVI (soil-adjusted and atmo- 310 spherically resistant vegetation index) [52], and EVI 311 (enhanced vegetation index) [53] were produced from 312 the atmospherically corrected and reflectance-based satel- 313 lite imagery. We also introduced a new vegetation index 314 in this work, the generalized difference vegetation index 315 (GDVI) developed by Wu [54] and in the form of

$$
\mathrm{GDVI}=\left(\rho_{N I R}^{n}-\rho_{R}^{n}\right) /\left(\rho_{N I R}^{n}+\rho_{R}^{n^{n}}\right)
$$


TABLE I

Location, Depth, And Number of Soll Samples and EM38 Measurements

\begin{tabular}{|c|c|c|c|c|c|c|}
\hline \multirow{2}{*}{ Pilot sites } & \multirow{2}{*}{$\begin{array}{l}\text { Number of soil profile } \\
\qquad(0-150 \mathrm{~cm})\end{array}$} & \multicolumn{3}{|c|}{$\begin{array}{l}\text { Number of surface soil samples } \\
\qquad(0-30 \mathrm{~cm})\end{array}$} & \multicolumn{2}{|c|}{ Number of EM38 readings } \\
\hline & & $\begin{array}{l}\text { Sep. 2011-Apr. } \\
2012 \\
\end{array}$ & $\begin{array}{l}\text { Supplemental } \\
\text { Jun.-Jul. } 2012 \\
\end{array}$ & Jun. 2013 & Mar.-Apr. 2012 & $\begin{array}{l}\text { Supplemental } \\
\text { Jun.-Jul. } 2012 \\
\end{array}$ \\
\hline Musaib & 13 & 30 & 6 & & 45 & 23 \\
\hline Dujaila & 5 & 17 & 6 & & 65 & 17 \\
\hline $\begin{array}{l}\text { West Gharraf } \\
\text { Shat-Al-Arab } \\
\text { Abu Khaseeb }\end{array}$ & $\begin{array}{l}4 \\
5\end{array}$ & $\begin{array}{c}22 \\
8\end{array}$ & 4 & & $\begin{array}{l}57 \\
54 \\
15 \\
\end{array}$ & 17 \\
\hline \multicolumn{7}{|l|}{ Transects } \\
\hline Transect 1-North & & 26 & & 13 & 60 & \\
\hline Transect 2-South & & 44 & & 11 & 132 & \\
\hline Total & 27 & & 187 & & & \\
\hline
\end{tabular}

where $\rho_{N I R}$ is the reflectance of the near-infrared band and $\rho_{R}$ is that of the red band, and $n$ is the power, an integer from 1 to $n$. When $n=1$, GDVI = NDVI. As Wu concluded [54], when $n=2$, GDVI is better correlated with LAI (leaf area index) in all biomes, and more sensitive to low vegetal biomes than other vegetation indices. However, with the increase of $n$ (e.g., $n=3$ and 4), GDVI becomes saturated and insensitive to densely vegetated areas (e.g., wheat cropland, forest). High-power GDVI is thence only relevant for application in sparsely vegetated dryland biomes (such as rangeland and woodland). Our earlier studies show that GDVI is a powerful salinity indicator [28], [29], [55]. We applied this index $(n=2)$ together with others in soil salinity modeling and mapping in this study.

Regarding NonVIs, as well as NDII (normalized difference infrared index) [56], TCB, PC1, and PC2, LST were derived from Landsat ETM+ images.

3) Derivation of the multiyear maxima of VI and nonVI images: An algorithm using IDL language was designed for this purpose. The multiyear maxima of VIs and NonVIs of the period of 2009-2012 were derived for each pixel in all pilot sites. For NonVIs, multiyear spring maxima, i.e., the maxima during the crop growing period from February 01 to April 15 (note: barley is harvested in the end of April) were also produced.

We have to mention that SPOT and RapidEye images do not contain any thermal band to derive LST and thus cannot be individually used for salinity modeling in our study. After resampling the pixels to $30 \mathrm{~m}$, their VIs (NDVI, SAVI, and GDVI) and NonVIs (PC1 and PC2) were integrated into those of Landsat $\mathrm{ETM}+$ to derive the maxima of VIs and NonVIs in each pixel.

4) Extraction of the maxima of each VI and nonVI corresponding to the field sampling locations: Both maximal images of VIs and NonVIs were converted into TIF format, and imported into ArcGIS to extract the maximal values corresponding to each sampling plot location.

5) Division of the vegetated and nonvegetated areas: A thresholding technique was applied to the multiyear-maximal NDVI to determine the thresh- 357 old for division of the vegetated and nonvegetated areas 358 followed by a mask operation.

6) Linking multiyear maxima with plot-scale measurements: 360 The extracted maxima of VIs and NonVIs were cou- 361 pled with their correspondingly averaged plot-level EM38 362 readings or laboratory-measured soil electrical conductiv- 363 ity using SYSTAT, a software for statistical analysis and 364 modeling, for salinity model development using multi- 365 ple linear regression analysis at the confidence level of 366 95\%. A positive correlation between salinity and LST, 367 PCs and TCB, and a negative correlation between salin- 368 ity and different VIs, especially GDVI and NDVI, were 369 observed. $\quad 370$ Two types of salinity models were obtained: a) spe- 371 cific salinity models for vegetated and nonvegetated areas 372 resulted from multiple linear regression modeling that 373 was applied to two groups of samples located in vege- 374 tated and nonvegetated areas and b) integrated salinity 375 models in which all samples in the same pilot site were 376 input for modeling but vegetated and nonvegetated areas 377 were separately treated.

7) Evaluation and application of the salinity models: To 379 understand whether the models obtained are operational, 380 the specific and integrated models were, respectively, 381 applied back to the maxima of VIs and NonVIs of the 382 period 2009-2012 to produce local-scale salinity maps. 383 These maps were evaluated against the ground-measured 384 data by linear regression model [29], [34]. If the agree- 385 ment between the measured and predicted salinity is 386 $\geq 80 \%$, the models developed are considered operational 387 at local-scale and the salinity maps are reliable.

\section{Regional-Scale Mapping}

1) Regional-scale modeling: Models obtained from any 390 pilot site cannot be directly applied to regional-scale 391 salinity mapping due to lack of spatial representative- 392 ness. That is why we proposed here a "multiscale 393 modeling" approach to upscale plot-level measurements 394 
TABLE II

Salinity Models for the Pilot Sites and the Whole Mesopotamia

\begin{tabular}{|c|c|c|c|c|c|}
\hline \multicolumn{2}{|c|}{ Scale } & Type & Salinity models & Error scope & Multiple $\mathrm{R}^{2}$ \\
\hline \multirow[b]{4}{*}{ Pilot } & \multirow{3}{*}{ Musaib } & \multirow{2}{*}{ Vegetated area } & $\mathrm{EM}_{\mathrm{V}}=-824.134+918.536 * \mathrm{GDVI}-754.204 * \ln (\mathrm{GDVI})$ & \pm 41.700 & 0.925 \\
\hline & & & $\mathrm{EM}_{\mathrm{H}}=-606.197-460.043 * \ln (\mathrm{GDVI})+245.086 * \operatorname{Exp}(\mathrm{GDVI})$ & \pm 48.559 & 0.862 \\
\hline & & Nonvegetated area & $\mathrm{EM}_{\mathrm{H}}=2608853.46+1842.4 \mathrm{LST}-554286.69 * \ln (\mathrm{LST})$ & \pm 51.217 & 0.846 \\
\hline & \multirow{3}{*}{ Dujaila } & \multirow{2}{*}{ Vegetated area } & $\mathrm{EC}==-2.87-23.27 \ln (\mathrm{GDVI})(\mathrm{dS} / \mathrm{m})$ & \pm 5.240 & 0.874 \\
\hline \multirow[t]{4}{*}{ Site scale } & & & $\mathrm{EM}_{\mathrm{V}}=535.403-487.905 \mathrm{GDVI}$ & \pm 64.168 & 0.729 \\
\hline & & Nonvegetated area & $\mathrm{EM}_{\mathrm{V}}=-2725.05+10.018 * \mathrm{LST}-509.494 * \mathrm{NDII}$ & \pm 73.23 & 0.650 \\
\hline & \multirow{2}{*}{$\begin{array}{l}\text { West } \\
\text { Gharraf }\end{array}$} & Vegetated area & $\mathrm{EM}_{\mathrm{V}}=-78.811-353.217 \ln (\mathrm{GDVI})$ & \pm 143.992 & 0.684 \\
\hline & & Nonvegetated area & $\mathrm{EM}_{\mathrm{V}}=-19337.102+63.795 * \mathrm{LST}$ & \pm 166.515 & 0.578 \\
\hline \multirow{2}{*}{\multicolumn{2}{|c|}{ Regional scale }} & Vegetated area & $\mathrm{EM}_{\mathrm{V}}=66.338-258.114 * \ln (\mathrm{GDVI})$ & \pm 88.882 & 0.717 \\
\hline & & Nonvegetated area & $\mathrm{EM}_{\mathrm{V}}=3055497.34+2161.09 * \mathrm{LST}-649347.93 * \ln (\mathrm{LST})$ & \pm 92.524 & 0.695 \\
\hline
\end{tabular}

Note: $\mathrm{EM}_{\mathrm{V}}$ and $\mathrm{EM}_{\mathrm{H}}$ can be converted into $\mathrm{EC}(\mathrm{dS} / \mathrm{m})$ from the regional transect sampling, i.e., $\mathrm{EC}=0.0005 \mathrm{EM}_{\mathrm{V}}^{2}-0.0779 \mathrm{EM}_{\mathrm{V}}+12.655\left(\mathrm{R}^{2}=\right.$ $0.8505)$; and $\mathrm{EC}=0.0002 \mathrm{EM}_{\mathrm{H}}^{2}+0.0956 \mathrm{EM}_{\mathrm{H}}+0.0688\left(\mathrm{R}^{2}=0.7911\right)$.

and high-resolution-derived models to regional-scale assessment. To do so, the data from different pilot sites, which are situated in different locations in Mesopotamia (Fig. 2), were integrated together for regional-scale modeling using the same multiple regression model.

2) Upscaling test and regional salinity mapping: Since we will use MODIS data (VIs and LST) for regional salinity mapping, it is still not clear whether the models developed from high-resolution data (e.g., Landsat and SPOT) are applicable to MODIS data. For this reason, the best salinity indicators as revealed in the previous steps, the multiyear maxima of GDVI, and the LST maxima of the crop growing period from February to April in 20092012 (of the frame 168-37) were linked, respectively, to the multiyear maxima of MODIS GDVI (calculated from MOD13Q1), and the maximal LST (MOD11A2) of the same period after resolution degradation of the Landsat data from 30 to $250 \mathrm{~m}$ and upgrading of LST data from $1000 \mathrm{~m}$ to $250 \mathrm{~m}$. This processing was aimed at minimizing the information loss or unrealistic improvement [54]. 1000 random points covering all land cover types such as barelands (deserts, bare soils, and bare rocks), saline soils, urban areas, rangeland, and croplands were generated. By removing those falling in roads and swamps, it was found that Landsat GDVI $\left(\mathrm{GDVI}_{\mathrm{L}}\right)$ is strongly correlated with MODIS GDVI $\left(\mathrm{GDVI}_{\mathrm{M}}\right)\left[\mathrm{R}^{2}=0.839\right.$ in (2)], and the same was obtained for Landsat LST and MODIS $\operatorname{LST}\left[\mathrm{R}^{2}=0.795\right.$ in $\left.(3)\right]$

$$
\begin{aligned}
\mathrm{GDVI}_{\mathrm{M}} & =0.7837 \mathrm{GDVI}_{\mathrm{L}}+0.1665 \text { or } \mathrm{GDVI}_{\mathrm{L}} \\
& =\left(\mathrm{GDVI}_{\mathrm{M}}-0.1665\right) / 0.7837
\end{aligned}
$$

$$
\begin{aligned}
\mathrm{LST}_{\mathrm{M}} & =0.7054 \mathrm{LST}_{\mathrm{L}}+90.496 \text { or } \mathrm{LST}_{\mathrm{L}} \\
& =\left(\mathrm{LST}_{\mathrm{M}}-90.496\right) / 0.7054
\end{aligned}
$$

Therefore, with relevant adjustment of MODIS GDVI and LST in line with (2) and (3), regional models developed from high resolution Landsat data are applicable to the adjusted MODIS data for regional salinity mapping.
For such upscaling test, one may also propose the same 428 random processing for multiple Landsat scenes against 429 MODIS data to get the average to evaluate the extendabil- 430 ity. Since the land cover types are the same in the region, 431 the results should be more or less similar to what we have 432 obtained.

3) Validation: The regional salinity map derived from the 434 MODIS data was evaluated against the field samples from 435 two regional transects (blue points in Fig. 2) to check its 436 reliability and accuracy.

\section{RESULTS AND DisCUSSION}

After the above processing, both local- and regional-scale 439 salinity models obtained are listed in Table II, and local-scale 440 and regional-scale salinity maps are presented in Figs. 3 and 4441 for discussion.

\section{A. Salinity Models and Maps}

As our test revealed in the Dujaila site [29], specific models 444 for vegetated and nonvegetated areas were not recommended 445 for salinity mapping due to their low reliability (e.g., <37\%). 446 Thus, what are presented in Table II are the integrated mod- 447 els taking all the samples into account, whereas vegetated and 448 nonvegetated areas were separated during the multiple linear 449 regression analysis in each pilot site. We see that among all 450 the VIs, GDVI or its variant such as $\ln ($ GDVI) is the most rep- 451 resentative indicator for vegetated areas, and LST (and NDII) 452 for nonvegetated areas in all pilot sites. By the way, for sites 453 Shat-Al-Arab and Abu Khaseeb, independent models were 454 not developed due to limited soil sample number ( 8 and 5, 455 respectively).

It is also noted that the salinity models obtained are different 457 from each other in all pilot sites; none of them can be directly 458 extended to regional-scale mapping due to spatial variability. 459 However, these models can reliably predict soil salinity with 460 an accuracy of about $82.57 \%$ in Dujaila and $83.01 \%$ in Musaib 461 against the field measured data. Hence, they were considered 462 operational for their respective pilot sites. 


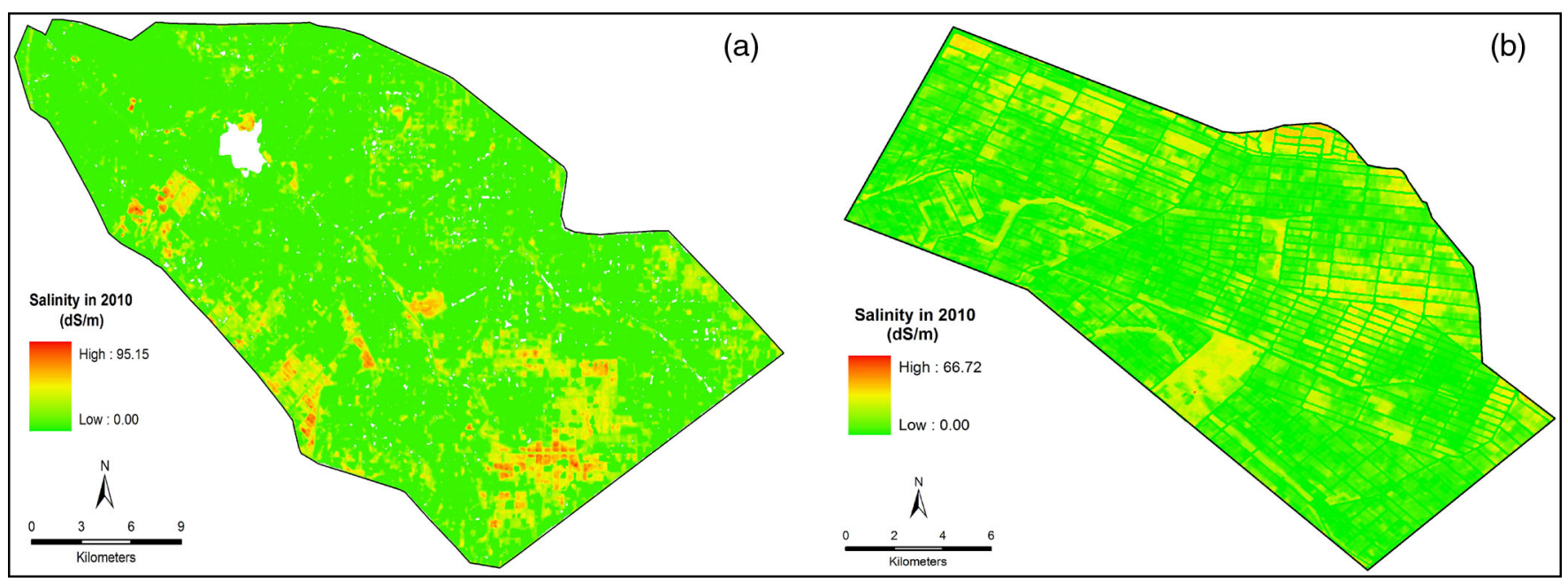

Fig. 3. Salinity of the pilot sites: (a) Musaib and (b) Dujaila.

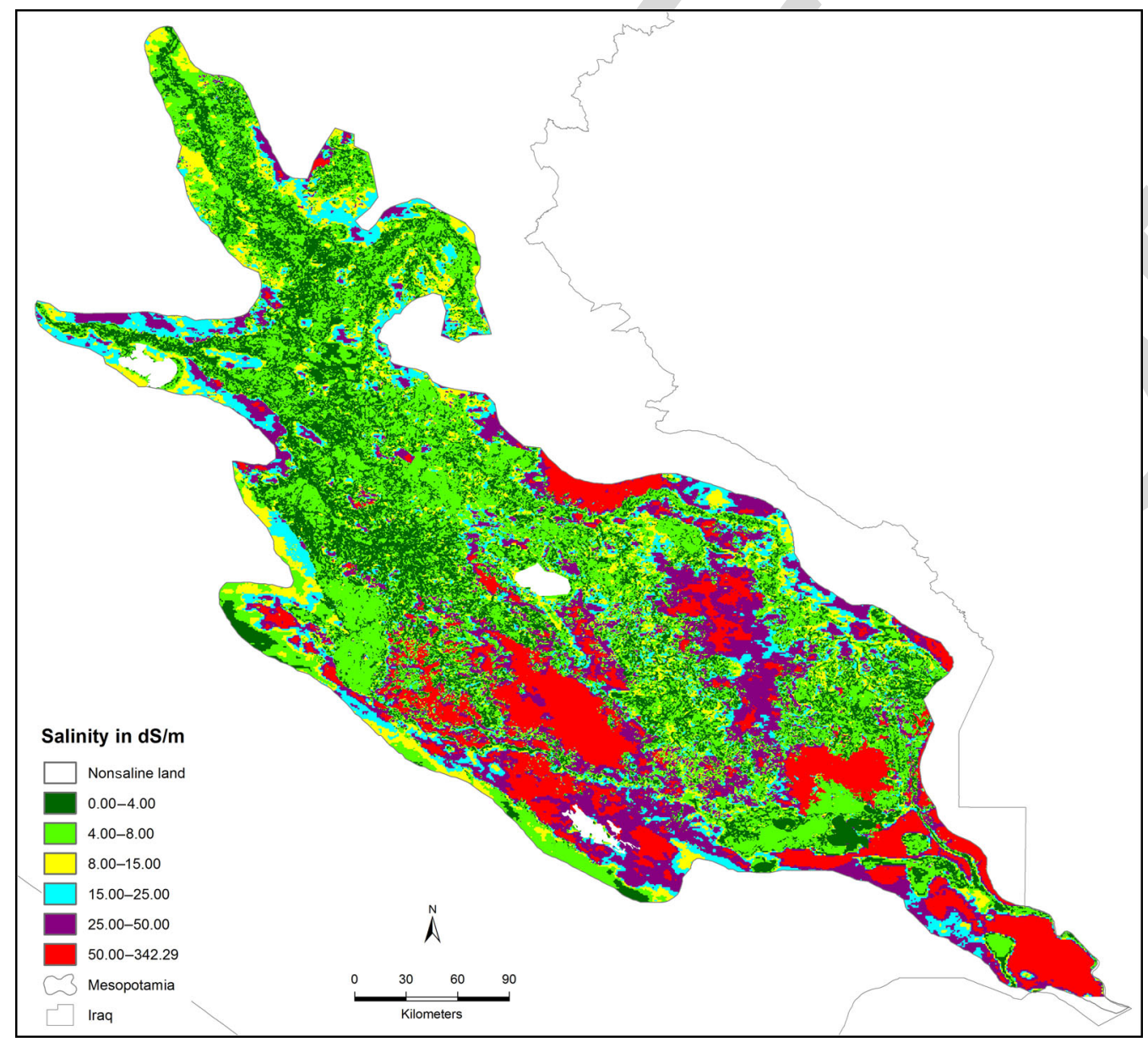

F4:1 Fig. 4. Present-state salinity map of Mesopotamia (expressed in EC classes as required by users).

For the regional-scale models, the multiple correlation coefficients $\mathrm{R}^{2}$ are relatively lower than those in pilot sites due to homogenization of samples from different pilot sites after integration; nonetheless, they have higher applicability in regionalscale mapping.
It is worth mentioning that most of the EM38 measurements 469 in spring (March-April) 2012 did not show any promising cor- 470 relation with VIs except for the Dujaila site perhaps due to 471 the problem of soil moisture after rainfall or irrigation while 472 measurements were undertaken in the field. For this reason, a 473 


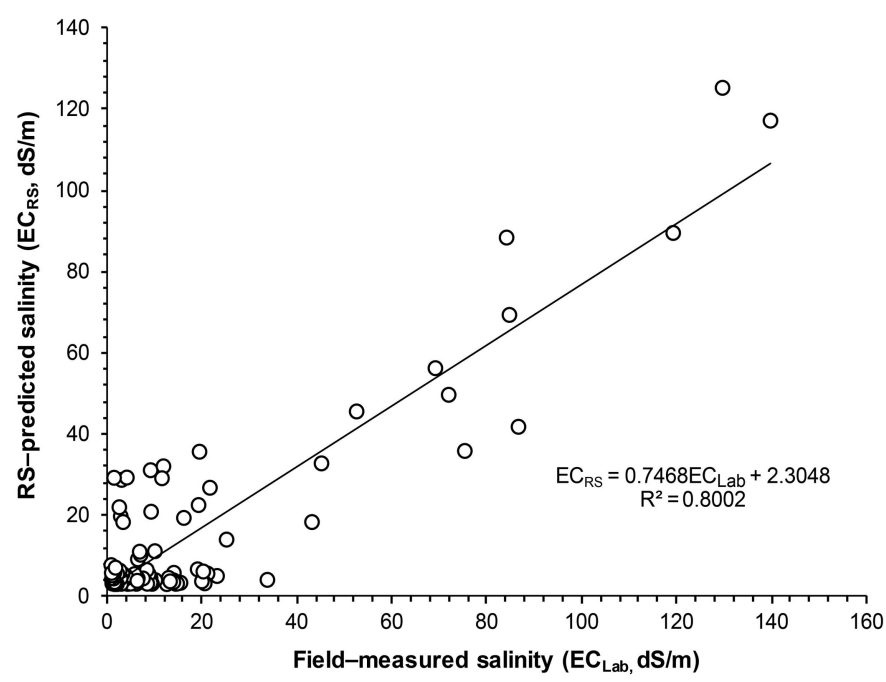

F5:1 Fig. 5. Agreement of the remote sensing-predicted salinity $\left(\mathrm{EC}_{\mathrm{RS}}\right)$ versus F5:2 field-measured salinity $\left(\mathrm{EC}_{\mathrm{Lab}}\right)$.

supplemental sampling campaign was carried out in the dry season after crops harvesting (June-July 2012). These EM38 readings show a good correlation with the multiyear maximal VIs and NonVIs in all pilot sites and were used for developing salinity models by multiple linear regression analysis. NDII and LST are of both vegetation and nonvegetation characters, and were included in the integrated salinity modeling for both vegetated and nonvegetated areas.

The local salinity maps of the present-state taking the sites Musaib and Dujaila as an example [Fig. 3(a) and (b)] are in a good agreement with ground data $\left(\mathrm{R}^{2}=0.830\right.$ in Musaib, and 0.826 in Dujaila). We consider that these maps are reliable.

As for the regional salinity map (Fig. 4), the accuracy evaluation revealed that 23 of the 121 regional samples taken along two transects and the surface EC of 27 soil profiles in pilot sites that were not used for modeling were abnormal due to internal problem of samples, most probably, derived from laboratory analysis (because the correlation among $\mathrm{Cl}^{-}, \mathrm{Na}^{+}$, and $\mathrm{EC}$ is very low, e.g., $R^{2}=0.047$ ); however, the remaining 98 samples show a good accordance with remote sensing predicted salinity. The observation accuracy is $80.9 \%$, and the statistical accuracy of the regional salinity map obtained by linear regression analysis at the confidence level of $95 \%$ is $80.02 \%$ (Fig. 5). Therefore, the regional map presented in Fig. 4 was considered reliable.

The agreement between the measured and remote sensing predicted salinity as shown in Fig. 5 is higher in the high salinity part than low salinity one. This is probably due to the fact that coarse-resolution LST has lower sensitivity to low salinity. An overestimation of about $2-10 \mathrm{dS} / \mathrm{m}$ may occur in some places in the weakly salinized areas. However, the sensitivity to low salinity can be improved if high resolution LST data are available.

One may have concern about the reasonability to use soil surface temperature, LST, as salinity indicator which was finally retained in the models for the nonvegetated areas. As Wu et al. [29] argued, it is commonly known that thermal conductivity of materials is temperature $(T)$-dependent, and the former is associated with electrical conductivity (EC).
However, the interrelationship between the thermal and 512 electrical conductivities is complex and may change signifi- 513 cantly depending on materials, e.g., soil types. Some authors 514 [5]-[7] have explored the possibility to use the thermal band 515 to identify the salt-affected soils but they have not discussed 516 the mechanism behind. Abu-Hamdeh and Reeder [57] ascer- 517 tained the relationship between thermal conductivity and salin- 518 ity, and found that thermal conductivity decreases with the 519 increase in the amount of added salts at given moisture content. 520 Sepaskhah and Boersma [58] found that the apparent thermal 521 conductivity is independent of water content at very low water 522 contents. Consequently, in driest condition (at lowest moisture 523 or water content), thermal conductivity is associated with the 524 salt amount-salinity. We believe, therefore, that LST-based 525 models are relevant for mapping salinity in nonvegetated areas. 526

Concern may also be addressed on the applicability of the 527 models. It is clear that the models obtained from pilot sites 528 are not recommended for direct application to similar areas for 529 salinity mapping without relevant adaptation. Of higher repre- 530 sentativeness, the regional-scale models can be disseminated to 531 the similar environment for this purpose.

\section{B. Assessment of the Integrated Processing Approach}

Different from the other authors (e.g., [10], [17], and [18]), 534 we used multiyear imagery dataset to derive the multiyear 535 maxima of VIs and NonVIs for multiscale salinity model- 536 ing followed with an upscaling analysis. The above-mentioned 537 problematic issues that are commonly faced in salinity mapping 538 by remote sensing were successfully minimized, and salinity 539 maps with high reliability were produced.

Despite a number of authors [10], [17] have conducted salin- 541 ity mapping and best band combination studies, but they used 542 single or multiple single images and did not differently treat the 543 vegetated and nonvegetated areas. Especially, authors [17] did 544 not take into account the nonvegetated area. Their approaches 545 cannot avoid the influences from crop rotation/fallow, and 546 moisture, which are often problematic in large area (or scale) 547 mapping. Hence, our approach has evident advantages over and 548 its uniqueness different from others.

However, some imperfection was also noted. As a matter 550 of fact, salinity has strong spatial variability; even in a small 551 $1 \times 1 \mathrm{~m}^{2}$ plot, salinity may change after each $20-30 \mathrm{~cm}$ inter- 552 $\mathrm{val}$, not to mention in the $250 \mathrm{~m}$ pixels of MODIS data which 553 were used for regional-scale mapping in this study. That is to 554 say, it is unlikely to produce a regional salinity map with an 555 accuracy of 2-3 dS/m based on the proposed methodology. 556 What can be done is to approach the reality as much as possible 557 by increasing the sampling number and density with a relevant 558 spatial distribution if both time and fund are available.

\section{Problems Confronted}

Though great efforts have been made, problem related to salt- 561 tolerant vegetation has not been completely resolved yet. In the 562 pilot sites, field sampling was well conducted and halophytes 563 were noted. But in other areas where sampling was not covered, 564 salinity may have been underestimated as salt-tolerant crops 565 
such as barley or other halophyte vegetation were not identified out for specific analysis. As was revealed by the experiment [3], barley has a rather strong resistance to salinity, and can still grow well with good production (1.68-1.84 tons/ha) in the field where soil salinity reaches $8-16 \mathrm{dS} / \mathrm{m}$ if fertilizer (e.g., nitrogen) is given.

The second issue is related to swamps and their surroundings, e.g., in the governorates of Thi-Qar and Basrah of Southern Iraq (Fig. 1). Moisture is almost a permanent problem for salinity mapping in these areas. Swamps can be excluded out for any salinity analysis but their surroundings are mostly moist vegetated area (locally cropland but mostly halophytes). In this mapping work, we tried to find the transitional part between moist ( $>345 \mathrm{dS} / \mathrm{m}$, the false salinity as LST model loses its sensitivity with increase of moisture) and nonmoist zones $(<345 \mathrm{dS} / \mathrm{m})$, and then treated the moist part as normal water body or swamp.

The third problematic issue is related to bareland. Due to security reasons, a number of sampling plots designed in the nonvegetated areas were not accessible. There were not enough samples from bare soil for model development and salinity map validation. Thus both salinity models and maps of the nonvegetated areas should be improved when security condition improves and more field data become available.

\section{CONCLUSION}

In spite of challenges, this study demonstrates the possibility to map and quantify the spatial distribution of the salt-affected land at regional-level based on the development of local- and regional-scale salinity models in Mesopotamia, Iraq. The validated maps we produced can be tentatively provided as a reference to decision-makers for facilitating their future land use planning in Mesopotamia. The proposed method can minimize the problems related to crop rotation/fallow practices, and soil moisture, and hence is different from other approaches. The models can be applied for multitemporal salinity mapping to track the temporal and spatial changes in the Mesopotamian plain and even in the whole country.

However, one weak point is noted, i.e., the approach cannot completely remove the influence from salt-tolerant crops such as barley, alfalfa, and cotton in the areas where no field survey was conducted. In addition, coarse resolution LST data (1000 $\mathrm{m})$ is really not ideal for such quantification as spatial variability of salinity has been greatly homogenized. Merely, these issues can be sorted out or improved when new thermal data with higher resolution (e.g., 60-250 m) are available, and field accessibility is improved.

In future work, as mentioned in the introduction, ET, as one of the indicators, can be taken into account together with others. In this way, remote sensing-based salinity models will be more comprehensive and relevant for both local- and regional-scale assessments.

The study was financially supported by ACIAR (Australian Center for International Agricultural Research) and the Italian
Government. The authors would like to thank Dr. M. Qadir 620 (UNU-INWEH), Mr. A. Platonov (IWMI-Tashkent), Dr. E. 621 Christen (CSIRO), and Dr. T. Oweis (ICARDA) for their coop- 622 eration in the early stage of the work; Dr. A. A. Hameed, 623 Dr. H. H. Al-Musawi (Ministry of Water Resources of Iraq), 624 and Dr. K. A. Saliem (Ministry of Agriculture of Iraq) for their 625 cooperation in field sampling; and Ms. B. Dardar (ICARDA) 626 for her assistance in a part of image processing.

\section{REFERENCES}

[1] FAO, Country Pasture/Forage Resource Profiles: Iraq, Rome, FAO, 2011, $34 \mathrm{pp}$.

[2] P. Buringh, Soils and Soil Conditions in Iraq. Baghdad, Iraq: Ministry of 631 Agriculture of Iraq, 1960, 337pp.

[3] P. J. Dieleman, Ed., Reclamation of Salt Affected Soils in Iraq. 633 Wageningen, The Netherlands: International Institute for Land 634 Reclamation and Improvement/Wageningen Publication, 1963, 175pp. 635

[4] T. Jacobsen and R. M. Adams, "Salt and silt in ancient Mesopotamian 636 agriculture," Science, vol. 128, pp. 1251-1258, 1958.

[5] B. Mougenot, M. Pouget, and G. Epema, "Remote sensing of salt-affected 638 soils," Remote Sens. Rev., vol. 7, pp. 241-259, 1993.

[6] J. A. Zinck, "Monitoring salinity from remote sensing data," in Proc. 1st 640 Workshop Eur. Assoc. Remote Sens. Lab. (EARSeL), Ghent University, 641 Belgium, 2001, pp. 359-368.

[7] G. I. Metternicht and J. A. Zinck, "Remote sensing of soil salinity: 643 Potentials and constraints," Remote Sens. Environ., vol. 85, pp. 1-20, 644 2003.

[8] J. Farifteh, A. Farshad, and R. J. George, "Assessing salt-affected soils 646 using remote sensing, solute modelling, and geophysics," Geoderma, 647 vol. 130, no. 3-4, pp. 191-206, 2006.

[9] M. D. Steven, T. J. Malthus, F. M. Jaggard, and B. Andrieu, "Monitoring 649 responses of vegetation to stress," in Proc. 18th Annu. Conf. Remote Sens. 650 Soc. Remote Sens. Res. Oper., U.K., 1992, pp. 369-377. 651

[10] M. Zhang, S. Ustin, E. Rejmankova, and E. Sanderson, "Monitoring 652 Pacific coast salt marshes using remote sensing," Ecol. Appl., vol. 7, 653 pp. 1039-1053, 1997.

[11] P. Brunner, H. T. Li, W. Kinzelbach, and W. P. Li, "Generating soil elec- 655 trical conductivity maps at regional level by integrating measurements 656 on the ground and remote sensing data," Int. J. Remote Sens., vol. 28, 657 pp. 3341-3361, 2007.

[12] T. Zhang et al., "Using hyperspectral vegetation indices as a proxy to 659 monitor soil salinity," Ecol. Indic., vol. 11, pp. 1552-1562, 2011. 660

[13] C. L. Wiegand, J. D. Rhoades, D. E. Escobar, and J. H. Everitt, 661 "Photographic and videographic observations for determining and map- 662 ping the response of cotton to soil salinity," Remote Sens. Environ., 663 vol. 49, pp. 212-223, 1994.

[14] N. Fernández-Buces, C. Siebe, S. Cram, and J. L. Palacio, "Mapping soil 665 salinity using a combined spectral response index for bare soil and vegeta- 666 tion: A case study in the former lake Texcoco, Mexico," J. Arid Environ., 667 vol. 65, pp. 644-667, 2006.

[15] D. B. Lobell, J. I. Ortiz-Monasterio, F. C. Gurrola, and L. Valenzuela, 669 "Identification of saline soils with multiyear remote sensing of crop 670 yields," Soil Sci. Soc. Amer. J., vol. 71, pp. 777-783, 2007.

[16] J. A. Poss, W. B. Russell, and C. M. Grieve, "Estimating yields of salt- 672 and water-stressed forages with remote sensing in the visible and near 673 infrared," J. Environ. Qual., vol. 35, pp. 1060-1071, 2006.

[17] R. S. Dwivedi and B. R. M. Rao, "The selection of the best possible 675 Landsat TM band combination for delineating salt-affected soils," Int. J. 676 Remote Sens., vol. 13, pp. 2051-2058, 1992.

[18] A. A. Eldeiry and L. A. Garcia, "Comparison of ordinary kriging, regres- 678 sion kriging, and cokriging techniques to estimate soil salinity using 679 Landsat images," J. Irrig. Drain. Eng., vol. 136, pp. 355-364, 2010.

[19] D. W. Roberts, T. I. Dowling, and J. Walker, "FLAG: Fuzzy landscape 681 analysis GIS method for dryland salinity assessment," CSIRO, Australia, 682 Tech. Rep. No 8/97, 1997 [Online]. Available: http://www.clw.csiro.au/ 683 publications/technica197/tr8-97.pdf, accessed on Oct. $2013 \quad 684$

[20] G. Metternicht, "Assessing temporal and spatial changes of salinity using 685 fuzzy logic, remote sensing and GIS. Foundations of an expert system," 686 Ecol. Model., vol. 144, pp. 163-177, 2001.

[21] D. Malins and G. Metternicht, "Assessing the spatial extent of dryland 688 salinity through fuzzy modeling," Ecol. Model., vol. 193, pp. 387-411, 689 2006. 
[22] W. Wu, "Monitoring land degradation in drylands by remote sensing," in Desertification and Risk Analysis Using High and Medium Resolution Satellite Data, A. Marini and M. Talbi, Eds. New York, NY, USA: Springer, 2009, pp. 157-169.

23] G. Metternicht, "Analysing the relationship between ground based reflectance and environmental indicators of salinity processes in the Cochabamba Valleys (Bolivia)," Int. J. Ecol. Environ. Sci., vol. 24, pp. 359-370, 1998.

[24] R. L. Dehaan and G. R. Taylor, "Field-derived spectra of salinized soils and vegetation as indicators of irrigation-induced soil salinization," Remote Sens. Environ., vol. 80, pp. 406-417, 2002.

[25] J. Farifteh, F. van der Meer, C. Atzberger, and E. Carranza, "Quantitative analysis of salt-affected soil reflectance spectra: A comparison of two adaptive methods (PLSR and ANN)," Remote Sens. Environ., vol. 110, pp. 59-78, 2007.

[26] L. Garcia, A. Eldeiry, and A. Elhaddad, "Estimating soil salinity using remote sensing data," in Proc. Central Plain Irrig. Conf., 2005, pp. 1-10 [Online]. Available: http://www.ksre.ksu.edu/irrigate/OOW/P05/Garcia pdf, accessed on Jan. 2013.

[27] L. Garcia, A. Elhaddad, J. Chavez, and J. Altenhofen, "Remote sensing to improve ET estimates," Presented at the Evapotranspiration Workshop Using Best Sci. Estimate Consumptive Use, Fort Collins, CO, USA, Mar. 12, 2010 [Online]. Available: http://ccc.atmos.colostate.edu/ET_ Workshop/pdf/12_Garcia.pdf, accessed on Dec. 2012.

[28] A. S. Mhaimeed, et al., "Use remote sensing to map soil salinity in the Musaib Area in Central Iraq," Int. J. Geosci. Geomatics, vol. 1, no. 2, pp. 34-41, 2013, ISSN 2052-5591.

[29] W. Wu et al., "Mapping soil salinity changes using remote sensing in Central Iraq," Geoderma Regional, vol. 2-3, pp. 21-31, 2014, doi: 10 . 1016/j.geodrs.2014.09.002.

[30] B. Rao et al., "Spectral behaviour of salt-affected soils," Int. J. Remote Sens., vol. 16, pp. 2125-2136, 1995.

[31] J. W. Rouse, R. H. Haas, J. A. Schell, and D. W. Deering, "Monitoring vegetation systems in the Great plains with ERTS," in Proc. 3rd ERTS-1 Symp., NASA SP-351, 1973, vol. 1, pp. 309-317.

[32] B. N. Holben, "Characteristics of maximum-value composite images for temporal AVHRR data," Int. J. Remote Sens., vol. 7, pp. 1435-1445, 1986.

[33] C. J. Tucker, C. L. Vanpraet, M. J. Sharman, and G. van Ittersum, "Satellite remote sensing of total herbaceous biomass production in the Senegalese Sahel: 1980-1984," Remote Sens. Environ., vol. 17, pp. 232-249, 1985.

[34] W. Wu, E. De Pauw, and U. Hellden, "Assessing woody biomass in African tropical savannahs by multiscale remote sensing," Int. J. Remote Sens., vol. 34, pp. 4525-4529, 2013.

[35] W. Wu, E. De Pauw, "Policy impacts on land degradation: Evidence revealed by remote sensing in western Ordos, China," in Land Degradation and Desertification: Assessment, Mitigation and Remediation, P. Zdruli et al., Eds. New York, NY, USA: Springer, 2010, pp. 219-232.

[36] J. Evans and R. Geerken, "Discrimination between climate and humaninduced dryland degradation," J. Arid Environ., vol. 57, no. 4, pp. 535554, 2004.

[37] W. Wu, E. De Pauw, and C. Zucca, "Use remote sensing to assess impacts of land management policies in the Ordos rangelands in China," Int. J. Digit. Earth, vol. 6, Suppl. 2, pp. 81-102, 2013.

[38] F. N. Kogan, "Application of vegetation index and brightness temperature for drought detection," Adv. Space Res., vol. 11, pp. 91-100, 1995.

[39] F. N. Kogan, "Global drought watch from space," Bull. Amer. Meteorol. Soc., vol. 78, pp. 621-636, 1997.

[40] Y. Bayarjargal et al., "A comparative study of NOAA-AVHRR derived drought indices using change vector analysis," Remote Sens. Environ., vol. 105, pp. 9-22, 2006.

[41] R. R. Gillies and T. N. Carlson, "Thermal remote sensing of surface soil water content with partial vegetation cover for incorporation into climate models," J. Appl. Meteorol., vol. 34, pp. 745-756, 1995.

[42] J. D. Kalma, T. R. McVicar, and M. F. McCabe, "Estimating land surface evaporation: A review of methods using remotely sensed surface temperature data," Surv. Geophys., vol. 29, no. 4-5, pp. 421-469, 2008.

[43] C. R. Hain, J. R. Mecikalski, and M. C. Anderson, "Retrieval of an available water-based soil moisture proxy from thermal infrared remote sensing. Part I: Methodology and validation," J. Hydrometeorol., vol. 10, pp. 665-683, 2009.

[44] H. Qiu. (2006). Thermal Remote Sensing of Soil Moisture: Validation of Presumed Linear Relation Between Surface Temperature Gradient and Soil Moisture Content [Online]. Available: http://people.eng.unimelb.edu. au/jwalker/theses/HuangQui.pdf, accessed on Aug. 2013.
[45] N. C. Coops and R. H. Waring, "The use of multiscale remote sensing imagery to derive regional estimates of forest growth capacity using 3-PGS," Remote Sens. Environ., vol. 75, pp. 324-334, 2001.

[46] I. Chaubey, K. Cherkauer, M. Crawford, and B. Engel, "Multiscale sensing and modeling frameworks: Integrating field to continental scales," Bridge, vol. 41, pp. 39-49, 2011.

[47] R. J. Kauth and G. S. Thomas, "The Tasseled cap-A graph descrip- 774 tion of the spectral-temporal development of agricultural crops as seen 775 by Landsat," in Proc. 2nd Int. Symp. Mach. Process. Remote Sens. Data, 776 Purdue University, West Lafayette, IN, USA, 1976, pp. 4B41-4B51. 777

[48] E. P. Crist and R. C. Cicone, "Application of the tasseled cap concept 778 to simulated thematic mapper data," Photogramm. Eng. Remote Sens., 779 vol. 50, pp. 343-352, 1984

[49] C. Huang, B. Wylie, L. Yang, C. Homer, and G. Zylstra, "Derivation of 78 a tasseled cap transformation based on Landsat 7 at-satellite reflectance," 782 Int. J. Remote Sens., vol. 23, pp. 1741-1748, 2002.

[50] M. W. Matthew et al., "Status of atmospheric correction using a 784 MODTRAN4-based algorithm," in Proc. SPIE Algor. Multispectral 785 Hyperspectral Ultraspectral. Imagery VI, 2000, vol. 4049, pp. 199-207. 786

[51] A. R. Huete, "A soil adjusted vegetation index (SAVI)," Remote Sens. 787 Environ., vol. 25, pp. 295-309, 1988.

[52] Y. J. Kaufman and D. Tanré, "Atmospherically resistant vegetation index 789 (ARVI) for EOS-MODIS," IEEE Trans. Geosci. Remote Sens., vol. 30, 790 no. 2, pp. 261-270, Mar. 1992.

[53] A. R. Huete, H. Q. Liu, K. Batchily, and W. van Leeuwen, "A comparison of vegetation indices global set of TM images for EOS-MODIS," Remote Sens. Environ., vol. 59, pp. 440-451, 1997.

[54] W. Wu, "The generalized difference vegetation index (GDVI) for dryland characterization," Remote Sens., vol. 6, pp. 1211-1233, 2014.

[55] W. Wu et al., "Salinity modeling by remote sensing in central and southern Iraq," presented at Fall Meeting, AGU, San Francisco, CA, USA, Dec. 3-7, 2012, Abstract B53H-07 [Online]. Available: http://abstract search.agu.org/meetings/2012/FM/ sections/B/sessions/B53H/abstracts/ B53H-07.html

[56] M. A. Hardisky, V. Klemas, and R. M. Smart, "The influences of soil salinity, growth form, and leaf moisture on the spectral reflectance of Spartina alterniflora canopies," Photogramm. Eng. Remote Sens., vol. 49, pp. 77-83, 1983. of density, moisture, salt concentration, and organic matter," Soil Sci. Soc. Amer. J. (SSSAJ), vol. 64, pp. 1285-1290, 2000.

[58] A. R. Sepaskhah and L. Boersma, "Thermal conductivity of soils as 809 a function of temperature and water content," Soil Sci. Soc. Amer. J. 810 (SSSAJ), vol. 43, no. 3, pp. 439-444, 1979

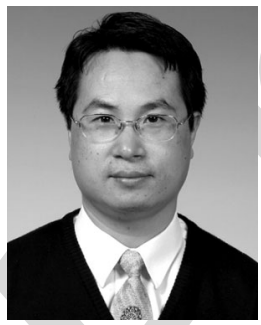

Weicheng $\mathrm{Wu}$ received the B.Eng. and M. Eng. degrees in earth sciences from the East China Geological Institute, Fuzhou, Jiangxi, China, in 1986814 and 1995, respectively, DESS (eq. to M. Eng.) degree 815 in environmental engineering from the University of 816 Paris XI (Paris-Sud), Orsay, France, in 1998, and 817 the $\mathrm{Ph} . \mathrm{D}$. degree in geography with specialization in 818 environmental geomatics (including remote sensing, 819 GIS, and spatial analysis) from the University of Paris 820 I (Panthéon-Sorbonne), Paris, France, in 2003.

In addition to his 11 years of university teaching 822 and research experience in China, he has gained 16 years of international expe- 823 rience in monitoring environmental changes and problems assessment, and land 824 resources investigation by remote sensing and GIS in Europe (France, Belgium, 825 and Italy) and in the Middle East. From 2005 to 2007, he was a Remote Sensing 826 Expert at NRD, University of Sassari, Sassari, Italy, and from 2007 to 2014, 827 Remote Sensing Specialist with ICARDA (International Center for Agricultural 828 Research in the Dry Areas), Amman, Jordan. He is currently an independent 829 scientist in Choisy-Le-Roi 94600, France.

He has played an active role, and partly coordinated and led in 24 national 83 and international cooperation research projects in China, France, Belgium, 832 and Italy and at ICARDA. He has published in total 63 scientific and tech- 833 nical papers, of which 32 are peer-reviewed and 31 are nonpeer-reviewed 834 conference/symposium papers. He serves as Reviewer for more than 12 ISI- 835 refereed and nonrefereed journals in remote sensing and geography. 836

His research interests include land characterization such as land use/cover 837 mapping, multitemporal and time-series change tracking, biomass and carbon 838 sequestration/emission analysis, land degradation assessment, water resources 839 accounting, crop production estimation, human-environmental interaction, and 840 impacts of climate change on water resources and food security. . , 70 . 773

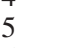

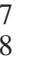
. (1)

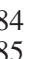
180
87
87

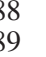

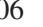
, .

\section{ii} 12 , , 


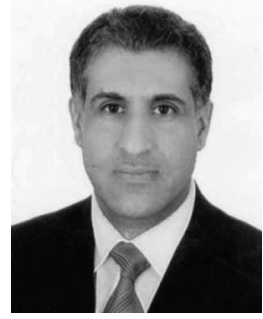

Waleed M. Al-Shafie was born in Baghdad, Iraq, in 1970. He received the B.S. and M.S. degrees in agricultural science, soil, and water resources from the University of Baghdad, Iraq, in 1994 and 2010, respectively.

From 2000 to 2003, he was an Assistant Researcher with IPA Agricultural Research Center, Department of Soil and Water, and from 2003 to 2007, Head of GIS Section, Ministry of Agriculture, Baghdad, Iraq. Since 2010, he has been in charge of the Manage-Planning and Follow-up Office of the AgroEcological Zoning (AEZ) Department, Ministry of Agriculture in Baghdad, and responsible for the implementation of land suitability maps for main crops in Iraq, while contributing to the development of the AEZ database which includes information of climate, soils, agricultural crops, and socioeconomic parameters for Iraq. His research interests include application of geographic information systems (GIS) and remote sensing for AEZ mapping, land suitability analysis, and salinity quantification.

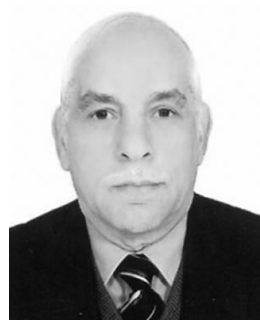

Ahmad S. Mhaimeed received the B.S. degree in soil science from Baghdad University, the M.S. degree in soil survey and classification from the University of Nebraska-Lincoln, Lincoln, NE, USA, and the Ph.D. degree in soil survey from Colorado State University, Fort Collins, CO, USA.

Of 30 years of academic experience, he is currently a Full-time Professor in Soil Survey and Land Management, and Head of the Desertification Control Department, College of Agriculture, Baghdad University, Baghdad, Iraq. He has presented many papers in national and international conferences and has published 3 books and more than 70 scientific papers. His research interests include soil survey and management using GIS and remote sensing.

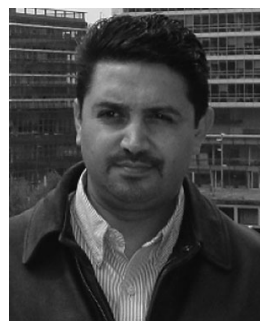

Feras Ziadat received the M.Sc. degree in soil conservation from the University of Jordan, and the Ph.D. degree in application of GIS and remote sensing for land use planning in arid areas from Cranfield University, U.K.

After his Ph.D., he worked with the University of Jordan as Associate Professor in Land Resource Management, GIS and remote sensing for 8 years. He currently works as a Soil Conservation and Land Management Specialist with the Integrated Water and Land Management Program, ICARDA. He has published over 44 refereed journal and conference proceedings in the area of land and water resources management. His research interests include sustainable land resource management and environmental modeling and monitoring with emphasis on the application of GIS and remote sensing on soil-landscape modeling and digital soil mapping, integrated and participatory land use planning and land evaluation, land degradation and desertification, land use changes, and integrated watershed management.

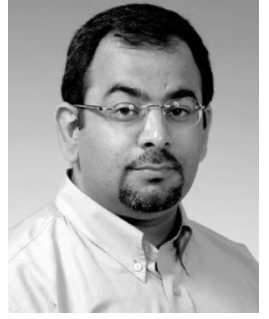

Vinay Nangia received the Ph.D. degree in water resources science and two M.S. degrees, one in biosystems and agricultural engineering and the 8 other in geographic information science, all from University of Minnesota, Minneapolis, MN, USA.

$\mathrm{He}$ is an Agricultural Hydrologist with the International Center for Agricultural Research in the 898 Dry Areas (ICARDA), Amman, Jordan. During a 899 9-year Postdoctoral research career, he has served as 900 a PI of co-PI on research projects worth about 5.75901 million, and authored or coauthored 59 technical pub- 902 lications that include 22 refereed journal articles in national or international 903 journals. He is an internationally recognized authority in hydrologic and water 904 quality modeling and GIS applications in water resources management. He has 905 offered more than 20 trainings (covering a total of 400 participants) on hydro- 906 logic modeling in 10 countries. He has served as Research Advisor/Committee 907 Member to M.S. and Ph.D. students and was a Visiting Assistant Professor 908 (2007-2011) with the Institute of Soil and Water Conservation, Chinese 909 Academy of Science, Beijing, China, where he co-advises graduate students. 910 Previously, he was a NSERC Visiting Fellow with Agriculture and Agri-Food 911 Canada conducting research on GHG emissions from sub-surface tile-drained 912 croplands of Eastern Ontario prior to which he was a Postdoctoral Fellow with 913 the International Water and Management Institute (IWMI), where he started his 914 career in 2005.

Dr. Nangia serves on the Editorial Board of professional society journals. 916

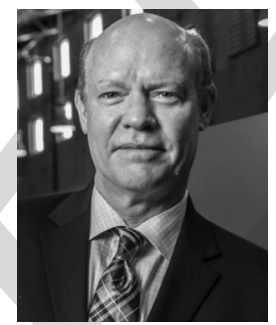

William Bill Payne received the B.A. degree in 917 chemistry from Wabash College, Crawfordsville, IN, 918 USA, in 1981, and the M.S. and Ph.D. degrees in 919 soil science from the Texas A\&M University, College 920 Station, TX, USA, in 1988 and 1990, respectively. 921

$\mathrm{He}$ is the recently appointed Dean of the College 922 of Agriculture, Biotechnology and Natural Resources 923 and Director of the Nevada Agricultural Experiment 924 Station,University of Nevada Reno, Reno, NV, USA. 925 From 2012 to 2014, he worked as Director of a \$150 926 million CRP1.1 research program with ICARDA 927 (International Center for Agricultural Research for the Dry Areas), Amman, 928 Jordan, aimed at improving food security and livelihoods in the dry areas 929 of the world. Prior to this, he served as a Professor of Crop Physiology 930 with Texas A\&M University, College Station, TX, USA, and is a for- 931 mer Research Director of the Norman Borlaug Institute for International 932 Agriculture.

He has published 11 books and book-chapters, 53 refereed journal papers, 934 and more than 100 nonrefereed conference abstracts and proceedings papers. $\quad 935$

Dr. Payne has been named Fellow of five international scientific societies 936 and has held numerous leadership roles at the state, national, and international 937 levels. 